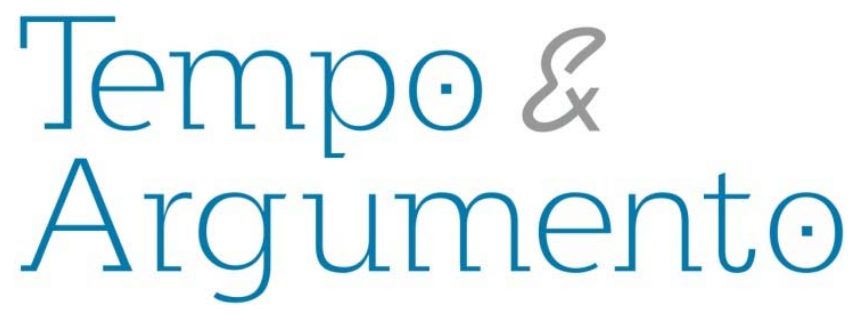

\title{
Ler, pesquisar e escrever história em tempos de internet: desafios e possibilidades
}

\begin{abstract}
Resumo
Apesar de toda a importância adquirida em nossa sociedade, a história da internet e os debates a respeito das relações entre história e internet têm sido praticamente ignorados pela maioria dos historiadores latino-americanos. Para preencher essa lacuna, o objetivo deste trabalho é apresentar o surgimento, o desenvolvimento e a configuração atual da internet, além de delinear as principais questões que envolvem sua influência e a das mídias digitais nas modalidades possíveis de pesquisa e escrita da história, o que implica tratar, em alguma medida, da chamada "história digital".
\end{abstract}

Palavras-chave: História; Historiografia; Internet - história.

\author{
George Zeidan Araújo \\ Doutorando em História pela Universidade \\ Federal de Santa Catarina - UFSC \\ Brasil \\ geoaraujo@ymail.com
}

\section{Para citar este artigo:}

ARAUJO, George Zeidan. Ler, pesquisar e escrever história em tempos de internet: desafios e possibilidades. Revista Tempo e Argumento, Florianópolis, v. 6, n. 12, p. 151 - 164, mai./ago. 2014. 


\title{
Reading, researching and writing History at internet times: challenges and possibilities
}

\begin{abstract}
Despite all the importance acquired by the Internet in our society, the History of the Internet and the debates involving the relationship between History and the Internet have been virtually ignored by most Latin American historians. Therefore, the aim of this paper is to present the emergence, development and current configuration of Internet, in addition to outline the main issues regarding the influence of the Internet and the digital medias on possible modalities historical researching and historical writing, which implies dealing, to some extend, of the so-called "Digital History".
\end{abstract}

Keywords: History; Historiography; Internet - history.

\section{Introdução}

Hoje em dia, dificilmente algum pesquisador ligado às ciências humanas e sociais deixaria de reconhecer a presença avassaladora que a internet adquiriu na vida pública e particularde parte considerável das pessoas ao redor do mundo. Presença observada em nossopróprio trabalho de pesquisadores. No que diz respeito às atividades relacionadas às áreas de educação, ensino e pesquisa, o uso é constante e diário. Entre as atividades rotineiramente desempenhadas, encontram-se: preenchimento online dos diários de classe; comunicação entre docentes e discentes via e-mail; busca de referências bibliográficas; uso de textos de periódicos acadêmicos (alguns deles de existência 
Não obstante, a história da internet e os debates a respeito das relações entre história e internet têm sido praticamente ignorados pela maioria dos historiadores latinoamericanos. Por isso, este trabalho se propõe apresentar o surgimento, o desenvolvimento e a configuração atual da internet, além de delinear as principais questões que envolvem sua influência e a das mídias digitais nas modalidades possíveis de pesquisa e escrita da história, o que implica tratar, em alguma medida, da chamada "história digital".

\section{Surgimento, desenvolvimento e configuração atual da internet}

A história da internet é um elemento constitutivo da história do desenvolvimento das tecnologias de mídia e de comunicação que tiveram um grande impulso a partir de meados do século XX. Esse desenvolvimento teria sido impossível sem o barateamento e a difusão dos computadores, até então dispositivos utilizados por um número bastante restrito de pessoas e limitados a tarefas muito específicas (BURKE; BRIGGS, 2006).

Apesar de ser difícil precisar uma data específica, uma vez que a internet se originou da confluência de elementos diversos, costuma-se afirmar que suas origens remontam ao ano de 1969. Em meados daquele ano, no contexto da Guerra Fria, a AdvancedResearchProjectsAgency (Arpa), criada onze anos antes pelo Departamento de Defesa dos EUA, desenvolveu uma rede de computadores denominada Arpanet. Essa rede deveria mobilizar recursos de pesquisa envolvendo a área computacional, com o escopo de tentar diminuir a então existente desvantagem tecnológica militar dos EUA com relação à URSS (RYAN, 2010, p. 11). Poucos anos depois, entre 1972-1973, a Arpanet foi conectada a duas outras redes, também administradas pela Arpa: a PRNET e a SATNET. Posteriormente, o Departamento de Defesa dos EUA criou uma rede para usos militares específicos, a Milnet, deixando a Arpanet (renomeada Arpa-Internet) somente para fins de pesquisa. Em 1984, a National Science Foundation (NSF) havia criado uma rede própria - a NFSNET -, que, a partir de 1988, passou a utilizar a Arpanet como infraestrutura 
física. Logo suplantada pela tecnologicamente mais avançada NFSNET, a Arpanet seria desativada em fevereiro de 1990.

Como a tecnologia de redes de computadores era de domínio público, a NFSNET foi deixando de ser controlada pela NFS, ao mesmo tempo em que o Departamento de Defesa dos EUA financiava a fabricação de computadores incluindo o protocolo TCP/IP, que se havia tornado padrão para a conexão entre computadores. Assim, na década de 1990, a maior parte dos computadores nos EUA era capaz de se conectar a alguma rede. Após a extinção da NFSNET, em 1995, o crescimento da internet sob provedores privados de serviços de rede foi exponencial e alcançou muito rapidamente a dimensão de uma rede global de redes de computadores. O próprio projeto original da Arpanetcontribuiu, sem dúvida, para que isso acontecesse, pois, além de contar com protocolos de comunicação abertos, a rede era descentralizada e reconfigurável, permitindo a adição contínua de novos nós. Também foram importantes a confluência da nova configuração da economia capitalista em processo de globalização, da cultura libertária existente entre os hackers ligados à comunidade dos usuários do sistema operacional UNIX (da qual fazia parte Linus Torvalds, o criador do núcleo Linux) e do projeto GNU, liderado pelo hacker Richard Stallman, que, posteriormente, fundaria a Free Software Foundation (CASTELLS, 2003, p. 15). Com a internet atraindo a atenção de um número crescente de pessoas, entre 1994 e 1995, várias revistas e outros meios de comunicação em diversos países passaram a divulgar as novidades e possibilidades que ela trazia.

Alguns teóricos e personalidades importantes do mundo da informática sustentam que, apesar de ter difundido e tornado usuais o acesso a redes de computadores, a visualização de web sites, a utilização de hiperlinks e o envio e recebimento de e-mails, essa "primeira internet" (ou "web 1.0") possuía uma série de limitações que seriam progressivamente superadas, até o estabelecimento, por volta de 2004, da chamada “web 2.0", estágio no qual a internet se encontraria atualmente. Não se sabe ao certo quando surgiu esse termo, popularizado a partir de 2004 por Tim O'Reilly, um entusiasta do movimento do software livre e do código-fonte aberto. Porém, se a internet passou por transformações significativas desde meados da década de 1990, a utilização do termo não é consensual entre teóricos e cientistas da computação. Vários deles, incluindo Tim 
Mas, de acordo com os defensores do uso da expressão "web 2.0", apesar das novidades trazidas pela "primeira internet” (web sites, hiperlinks, e-mails, etc.), as páginas ainda seriam uma espécie de "cópia digital do papel”, e os usuários apenas consumiriam passivamente o conteúdo nelas existente através dos navegadores. A web 2.0, ao contrário, estaria baseada em premissas distintas, que possibilitariam a vivência de outros tipos de experiências relacionadas à inventividade e à criatividade. Com a possibilidade não só de acessar, mas também de alterar o conteúdo de uma página online sem necessidade de conhecimento sobre edição de páginas web, o ato de ler tornar-se-ia imediatamente simultâneo ao de escrever, e ambos teriam uma forte dimensão coletiva (NEITZEL, 2010, p. 88-89). Dimensão essa que teria sido ainda mais potencializada pela possibilidade de colaboração em massa dos usuários através da internet, e bastante facilitada pela crescente utilização da aplicação web conhecida como wiki, inventada entre 1993 e 1994 pelo programador norte-americano Howard G. "Ward" Cunningham. O mais bem-sucedido exemplo de utilização dos recursos wikié a Wikipédia, uma enciclopédia multilíngue, colaborativa,online, de licença livre. A versão em inglês dessa enciclopédia, lançada no começo de 2001 por Jimmy Wales (um empresário do ramo da internet) e Larry Sanger (um desenvolvedor de software), conta, atualmente, com cerca de cinco milhões de verbetes.

\section{História digital: desafios e possibilidades}

\section{História digital, história virtual ou história hipertextual?}

Como a história digital ainda é algo relativamente recente, os historiadores sequer decidiram como classificá-la. Com efeito, ela tem sido considerada tanto uma tendência historiográfica, quanto uma metodologia específica, um subcampo na história, ou mesmo um novo paradigma historiográfico (LUCCHESI, 2014, p. 15-16). 
Além disso, existe também certo desacordo entre os historiadores quanto à nomenclatura a ser adotada para essa "novidade historiográfica”, podendo-se encontrar designações como história digital, história virtual ou ainda história hipertextual. No Brasil, embora muitos historiadores empreguem o termo história digital, outros preferem história virtual (BARROS, 2010, p. 32). Por esse motivo, antes de prosseguir, talvez seja útil sublinhar que a denominação história virtual há muito é um sinônimo, nos países anglófonos, da assim chamada história contrafactual (por vezes também referida como história alternativa), da qual um dos principais representantes é o conservador britânico Niall Ferguson. Nesse tipo de historiografia, algo popular nesses países, é comum que os historiadores se dediquem a exercícios mentais, imaginando cenários alternativos derivados de modificações no curso de eventos considerados importantes, como a Expansão Ultramarina Europeia ou a Revolução Francesa (PELEGRÍN CAMPO, 2010). Assim, preferimos utilizar o termo história digital por sua aceitação global cada vez maior pelos historiadores. Sublinhe-se, entretanto, que historiadores de alguns centros importantes, como a Itália, preferem a utilização da expressão "historiografia digital” (storiografiadigitale) (RAGAZZINI, 2004).

\section{Leitura histórica e internet}

Sem dúvida, as transformações socioculturais acarretadas pelo uso em larga escala da internet alteraram também várias das atividades que costumam ser desempenhadas pelos profissionais que se dedicam à história, bem como reconfiguraram antigas modalidades (POIRRIER, 2010, p. 468). Neste sentido, refletir sobre os desafios e possibilidades da história digital passa, necessariamente, pela indagação sobre como as características dos dispositivos utilizados para a leitura afetam taisatividades.

A leitura feita em meio digital, diante da tela (seja em um web site, artigo em um periódico ou trecho de um livro digital), pode ser problemática, pois, geralmente, é descontínua e costuma engendrar uma fragmentação da própria obra, documento ou meio através do qual são veiculados. Leitura que muitas vezes é feita apenas através da busca de palavras-chave específicas, que não atenta para a identidade e coerência textual 

23).

\section{Pesquisa histórica e internet}

Por sua vez, o conjunto das atividades relacionadas à pesquisa histórica foi substancialmente alterado pela internet, tanto pela modificação de práticas antes existentes, como pela incorporação de novas. Entre as novas práticas incorporadas destacam-se, principalmente, as visitas interativas ao acervo de museus virtuais, a consulta a fontes digitalizadas, a participação em fóruns especializados e redes sociais online que discutem temáticas relacionadas à história e à historiografia, etc.

Contudo, não é demais lembrar que as recomendações básicas do ofício de historiador, aprendidas ao longo da formação (como um olhar crítico na análise dos fatos e uma minuciosa crítica das fontes), não devem ser descartadas pelo advento da internet e dos meios digitais. Em outras palavras, o historiador deve valer-se das técnicas disponibilizadas pela tecnologia da internet e dos meios digitais para a realização de sua pesquisa, seguindo sempre os preceitos da profissão (GALLINI; NOIRET, 2011, p. 17). Estes é que devem moldar a utilização das técnicas, e não o contrário. Aliás, como bem afirma Pierre Lévy, teórico cultural especializado nas implicações cognitivas e culturais das tecnologias digitais, as técnicas logicamente influem nas estruturas cognitivas, nas operações executadas na rede, nos modos das associações que nela se desenvolvem e também na velocidade comque se transformam e circulam. Mas, por si sós, não determinam, em última instância, nenhum desses fatores (LÉVY, 1993, p. 186).

Por outro lado, é certo que a internet, a leitura e a escrita em meio digital, ao disponibilizarem uma série de ferramentas de trabalho mais práticas, mais baratas e mais rápidas, afetaram - alguns historiadores chegam a dizer que "revolucionaram" decididamente os modos e tempos da investigação histórica: 
A disponibilidade de ferramentas de trabalho mais cômodas, mais baratas (ainda que muitas bibliotecas científicas digitais requeiram subscrição) e mais rápidas é por si só uma revolução, e é a dimensão mais imediatamente perceptível do enorme ganho que a Internet representa para a investigação histórica, em particular para quem dela se ocupa estando em países sem grandes recursos bibliográficos nem facilidade de acesso aos maiores acervos bibliográficos mundiais. Bastaria pensar em como se modificaram a maneira e os tempos para compilar uma ampla bibliografia de referência. [...] [É] possível consultar catálogos de bibliotecas no mundo, um privilégio que - é útil recordá-lo - antes estava reservado a quem podia empreender uma viagem (real) de estudo em algum dos templos de conservação bibliotecária (GALLINI; NOIRET, 2011, p. 18).

Apesar disso, nem tudo se tornou necessariamente mais fácil ou mais prático para a pesquisa histórica. Se a utilização de um recurso de hipertexto, como os hiperlinks, possibilitaque determinado manuscrito, discurso, testamento, sentença judicial, qualquer fonte primária, enfim, mencionada em algum texto digital, blog ou página da internet esteja ao alcance de um clique (ALMEIDA, 2011), é preciso prestar atenção às dificuldades que podem surgir no momento de citar ou organizar as referências dispersas, fragmentadas, cambiantes e de natureza múltipla obtidas na internet. Dificuldades práticas e também teóricas, já que dizem respeito, igualmente, às condições de transmissão e conservação do saber histórico (GALLINI; NOIRET, 2011, p. 19).

Outro aspecto importante a ser levado em conta é o estatuto das publicações eletrônicas na internet (incluindo as teses e dissertações disponibilizadas online), envolto em uma série de questões éticas, legais e editoriais ainda pouco discutidas, que versam sobre o "[...] status quo do processo de comunicação acadêmica enquanto sistema tecnológico" (SABBATINI, 2005, p. 27). Qual seria a melhor forma de se combater o plágio digital? Como as instituições de fomento à pesquisa poderão manter o financiamento dos pesquisadores tendo em vista as somas cada vez mais altas que as editoras exigem para a liberação do material bibliográfico que esses mesmos pesquisadores produziram e de que necessitam para dar prosseguimento à sua investigação? Como conciliar as pressões cada vez maiores - advindas tanto da sociedade civil, como de um número crescente de pesquisadores e estudantes - pelo acesso livre à informação com os obstáculos que as editoras comerciais impõem a tal acesso coma lei de direitos autorais? A avaliação por pares não acabaria transformando os avaliadores em comentadores e, em alguns casos, 
material publicado diante de um hipotético defeito nos servidores que armazenam esse material? É possível maximizar a segurança dos dados fornecidos por autores e leitores, sabendo-se que grande parte do tráfego da rede está sujeitaà interceptação por parte de pessoas mal-intencionadas? (SABBATINI, 2005, p. 28-36).

Apesar da pouca atenção dada a esses importantes questionamentos,tornaram-se corriqueiras a consulta e a utilização de uma infinidade de publicações eletrônicas disponíveis na internet. Porém, se é possível - ainda que muitas vezes mediante subscrição e, mesmo assim, com restrição de acesso - consultar e mesmo obter textos antes totalmente inacessíveis através de algumas das grandes bases bibliográficas eletrônicas, como o Jstor ou o Project Muse, há algumas limitações. Existem limitações temporais devido ao intervalo entre o que é publicado e o que é disponibilizado online. Além disso, há limitações geopolíticas que decorrem do fato de que a grande maioria das publicações oferecidas está disponível apenas em inglês e/ou foi produzida por pesquisadores de alguma maneira relacionados ao mundo anglófono (GALLINI; NOIRET, 2011, p. 21-22).

\section{Escrita da história e internet}

No que tange às implicações, ainda um tanto quanto nebulosas, do uso dos meios digitais e da internet para as modalidades possíveis de escrita da história, a maioria dos debates gira em torno da influência exercida pelos pressupostos da assim chamada "web 2.0", e englobariam "a transformação rumo à arquitetura hipertextual, a disponibilidade de fontes primárias e secundárias digitalizadas e a dimensão coletiva da produção histórica" (GALLINI; NOIRET, 2011, p. 24). Como já tratamos dos dois primeiros pontos, o enfoque agora recairá sobre a dimensão coletiva da produção histórica.

Talvez essa dimensão coletiva da produção histórica, proporcionada pelo estágio atual da internet, seja justamente a que os estudiosos têm considerado como a mais 
intrigante e capaz de modificar irreversivelmente o alcance e o estatuto do conhecimento histórico, na medida em que enceta uma modificação na relação entre o historiador e seu público. Tendo isso em mente, alguns autores chegam a falar em uma "história digital 2.0." que, por sua vez, formaria parte do que às vezes vem sendo chamado de "Ciências Humanas Digitais" (NOIRET, 2012, p. 21-22). De fato, a possibilidade de que existam textos de autoria múltipla - por vezes, anônima - e em constante modificação abala algumas das mais antigas tradições no campo da história: a do trabalho atribuído quase sempre aum único indivíduo e não passível de modificações após sua publicação (a não ser, é claro, em caso de desejo do autor em função de uma possível reedição). A maioria dos historiadores atuais ainda tem dificuldade em conceber um trabalho que não obedeça a esses parâmetros (ROSENWEIG, 2011).

Vinculada a essa temática, encontra-se outra, também muito cara aos historiadores: a da narrativa histórica. De acordo com um dos maiores entusiastas da história digital, o historiador norte-americano Edward L. Ayers, ainda que representem um enorme desafio, as possibilidades combinadas do hipertexto e da autoria múltipla podem proporcionar narrativas históricas mais ricas, precisas e detalhadas que a história produzida por um único indivíduo e disposta em papel:

Teremos que conceber novas maneiras de argumentar e de fazer associações, de dispor evidências e documentação para nossas asserções. Teremos que pensar sobre formas de construir narrativas em camadas ou ramificadas ou entrelaçadas, ou anotadas e indexadas profunda e dinamicamente. Teremos que pensar sobre a escolha entre narrativas complexas internamente que são limitadas e fixas mesmo se pensarmos acerca das narrativas incorporadas em redes que, portanto, crescem e se modificam. Teremos que pensar sobre uma nova estética da narrativa histórica. Teremos que pensar nas distinções entre ler história e fazer história, sobre o locus da autoridade. Se pudermos chegar a respostas viáveis a esses desafios [...] a história hipertextual poderia tornar-se a mais sofisticada forma de narrativa histórica. Sob essa forma, ela poderia unir a análise e a evidência de uma forma rigorosa, impossível [de ser alcançado] em uma página impressa. [...] [A] história hipertextual poderia oferecer uma história mais rica que nossas tecnologias mais antigas permitiram, permitindo-nos abraçar a complexidade da maneira que temos almejado (AYERS, 1999a). 
Tanto o problema da autoria múltipla de um texto em perpétua modificação, quanto as novas possibilidades de narrativa histórica tocam em pontos muito sensíveis do campo da história. Contudo, mesmo com todas as dificuldades que o debate de assuntos de tal natureza possa provocar, sua discussão no momento atual é de fulcral importância para o estatuto da história enquanto ciência humana.

\section{Considerações finais}

Ler, pesquisar e escrever história sem que isso implique, em alguma medida, o uso da internet e dos meios digitais parece hoje assaz difícil. Como procuramos mostrar, esse uso tem levantado uma série de questões relativas ao estudo, à pesquisa histórica e à escrita da história que ainda precisam de uma análise mais cuidadosa por parte dos historiadores.

Como a internet e os meios digitais passam atualmente por transformações muito rápidas, há, sem dúvida, alguma desorientação e confusão nas tentativas de se oferecer respostas, ainda mais em uma época na qual, como aponta Dominique Wolton (um especialista nos estudos da comunicação e suas relações com as mídias, o espaço público, e astecnologias), coexistem deslumbramento e desinformação com relação às novas mídias e técnicas (WOLTON, 2007, p. 11-12). Por isso mesmo, apenas um debate consequente e constante pode avançar na busca de um estatuto teórico-metodológico adequado aos desafios que a internet e os meios digitais representam para o campo da história. Por outro lado, parece que o debate exigido pede uma abordagem transdisciplinar que ultrapassa o âmbito da disciplina histórica (LUCCHESI, 2014, p. 19).

Do ponto onde estamos, como vislumbrar o presente e o futuro da prática histórica? Para Cohen e Rosenzweig, por exemplo, os historiadores devem enfrentar os problemas relativos aqualidade, durabilidade, legibilidade, confiabilidade e acessibilidade do conteúdo histórico que continua a se expandir na internet. Segundo os autores, não é razoável deixá-los a cargo de tecnólogos, legisladores e empresários, ou mesmo se contentar que deles se ocupem os colegas que trabalham em arquivos e bibliotecas (COHEN; ROSENZWEIG, 2006, p. 13). No mesmo tom, Ayers defende que os próprios 
historiadores deverão se responsabilizar pela reafirmação da validade do conhecimento histórico e defender a existência da disciplina. Eles também devem decidir se, valendo-se da internet e dos meios digitais, construirão uma história verdadeiramente hipertextual, se essa nova história terá as feições de uma renovada ciência social da história, se será algum tipo novo de história imersiva, ou, mesmo, se irá configurar-se em uma história na qual todas essas alternativas estejam combinadas (AYERS, 1999b).

O futuro da história, portanto, em todas as suas vertentes e possibilidades, continua em aberto. E como a disciplina histórica está frequentemente questionando suas relações com a filosofia, a ciência e a literatura,talvez o melhor caminho seja procurar aproveitar as ferramentas disponíveis em nossa época para ajudar a escrever mais um capítulo da história da historiografia.

\section{Referências}

ALMEIDA, Fábio Chang de. O historiador e as fontes digitais: uma visão acerca da internet como fonte primária para pesquisas. In: Aedos, n. 8, v.3, jan./jun. 2011. Disponível em <http://seer.ufrgs.br/aedos/article/view/16776/11939>. Acesso em: 25 mar. 2014.

AYERS, Edward L. History in Hipertext. 1999a Disponível em <http://www.vcdh.virginia.edu/Ayers.OAH.html>. University of Virginia, .Acesso em: 31 mar. $/ 2014$.

AYERS, Edward L.. The Pasts and futures of digital history. 1999b. Disponível em <http://www.vcdh.virginia.edu/PastsFutures.html>. Universityof Virginia, Acesso em: 31 mar. 2014.

BARROS, José D'Assunção. Fontes históricas:um caminho percorrido e perspectivas sobre os novos tempos. Revista Albuquerque, v. 3, n. 1, 2010, p.00-00.

BURKE, Peter; BRIGGS, Asa. Uma história social da mídia: de Gutenberg à internet. Rio de Janeiro: Jorge Zahar , 2006.

CASTELLS, Manuel . A Galáxia da internet: reflexões sobre a internet, os negócios e a sociedade. Rio de Janeiro: Jorge Zahar , 2003. 
CHARTIER, Roger. Línguas e leituras no mundo digital. In: . Os desafios da escrita. São Paulo: Editora Unesp, 2002.

COHEN, Daniel I.; ROSENZWEIG, Roy. DigitalhHistory: A Guide to Gathering, Preserving, and Presenting the Past on the Web. Filadélfia: University of Pensylvania Press, 2006.

GALLINI, Stefania; NOIRET, Serge. La historia digital en la era del Web 2.0. Introducciónaldossier Historia digital. In: Historia crítica, n. 43, Bogotá, 2011, p. 16-37. Disponível em <http://historiacritica.uniandes.edu.co/view.php/691/index.php?id=691>. Acesso em: 11 mar. 2014.

LÉVY, Pierre. As tecnologias da inteligência: O Futuro do pensamento na era da informática. Rio de Janeiro: Editora 34, 1993.

LUCCHESI, Anita. Digital history e storiografiadigitale : estudo comparado sobre a escrita da história no tempo presente (2001-2011). 2014. Dissertação (Mestrado) - Universidade Federal do Rio de Janeiro, Instituto de História, Rio de Janeiro.

NEITZEL, Luiz Carlos. Informatização: ponte, trincheira ou muro? In: NEITZEL, Luiz Carlos; NEITZEL, Adair de Aguiar (Orgs.). Leitura e produção em meio digital. Florianópolis: Edufsc, 2010.

NOIRET, Serge. La digital history: histoireetmémoire à laportée de tous. In: MOUNIER, Pierre (dir.). Read/Write Book 2: une introduction aux humanitésnumériques. Marselha: OpenEdition Press, 2012. Disponível em <http://books.openedition.org/oep/258>. Acesso em: 30 mar. 2014.

PELEGRÍN CAMPO, Julián. La historia alternativa como herramientadidáctica: una revisión historiográfica. In: Clío: History and histoy teaching, Saragoça, n. 36, , 2010. Disponívelem<http://clio.rediris.es/n36/articulos/pelegrin.pdf>.Acessoem: 30 mar. 2014.

POIRRIER, Philippe. Internet et les historiens. In: DELACROIX, Christianet al.(Org.). Historiographies: Conceptsetdébats, Paris, Gallimard, 2010.

RAGAZZINI, Dario. La nascitadellastoriografiadigitale. In: - (Org.). La storiografiadigitale. Torino: UTET Libreria, 2004.

ROSENZWEIG, Roy. Wikipedia: can history be open source? In: .Clio Wired: the future of the past in the digital age. Nova York: Columbia University Press, 2011.

RYAN, Johnny. A history of the internet and the digital future. Londres: Reaktion Books, 2010.

SABBATINI, Marcelo. Publicações eletrônicas na Internet. São Caetano do Sul: Yendis Editora, 2005. 
WOLTON, Dominique [2000]. Internet, e depois? Uma teoria crítica das novas mídias. Porto Alegre: Sulina, 2007. 